Int. J. Environ. Res. Public Health 2007, 4(4), 260-267

International Journal of

Environmental Research and Public Health

ISSN 1661-7827

www.ijerph.org

(C) 2007 by MDPI

\title{
Effects of $\alpha$-Tocopherol on Oxidative Status and Metabolic Profile in Overweight Women
}

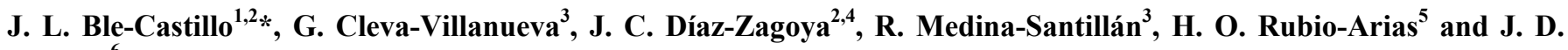 \\ Méndez \\ ${ }^{1}$ General Hospital, Zone 46, IMSS, Prolongación de Avenida Universidad Km 2.5, Colonia Casa Blanca, 86060, Villahermosa, \\ Tabasco, México \\ ${ }^{2}$ Research Station in DACS, Juarez Autonomous University of Tabasco, Ave. Universidad No 2890, Colonia Tamulte, \\ Villahermosa Tabasco, C.P. 86100, México \\ ${ }^{3}$ Superior Medicine School of the National Polytechnic Institute, México, D.F., México \\ ${ }^{4}$ Faculty of Medicine, National Autonomous University of Mexico, México D.F., México. \\ ${ }^{5}$ Faculty of Zootechnic, Autonomous University of Chihuahua, Mexico \\ ${ }^{6}$ Hospital de Especialidades, CMN Siglo XXI, IMSS, Av. Cuauhtémoc 330, Col. Doctores 06725, México D.F., México \\ *Correspondence to Dr. J. L. Ble-Castillo; Email: jorgeble@hotmail.com
}

Received: 01 October 2007 / Accepted: 30 November 2007 / Published: 31 December 2007

\begin{abstract}
Despite extensive research, the effects of $\alpha$-tocopherol supplementation remain controversial. Few studies have been focused on obese and overweight people. We examined the effects of $\alpha$-tocopherol (AT) on the oxidative status and metabolic profile in overweight women. Sixteen overweight women between the ages of 40-60 years old, received AT, $800 \mathrm{IU} /$ day during 12 weeks, followed by a 6-week washout period. Blood samples were taken at the beginning and then every 6 weeks until the end of the study. AT, retinol, malondialdehyde (MDA), total antioxidant status (TAS), selenium-dependent glutathione peroxidase (GPx) and CuZn-superoxide dismutase (SOD) were quantified to evaluate the oxidative stress. The metabolic profile was estimated by measuring glycated hemoglobin ( $\mathrm{HbAlc})$ in erythrocytes and glucose, phosphate, magnesium, lipid and lipoprotein concentrations in serum. Under AT administration HbA1c, serumMDA levels and erythrocyte GPx activity were markedly reduced. TAS, AT and $\mathrm{Mg}^{2+}$ concentrations in serum and SOD activity in erythrocytes were higher after AT treatment. Body weight; glucose, lipid and retinol concentrations, or blood cells count were unchanged. Lipid peroxidation was considerably reduced in AT treated women and also improved serum antioxidant status was observed, but the imbalanced response between erythrocyte SOD and GPx activities could affect normal response to oxidative stress.
\end{abstract}

Keywords: $\alpha$-tocopherol, oxidative stress, lipid peroxidation, overweight

\section{Introduction}

In spite of widespread supplementation use of vitamin $\mathrm{E}$, there is not a complete understanding of its potential benefit. Some reports have shown beneficial effects in experimental models based upon AT antioxidant property to inhibit lipid peroxidation $[1,2]$. However, others in vivo studies have suggested that AT can also act as a prooxidant molecule under certain circumstances [3, 4]. In the last two years, a study showed AT safety across a broad range of doses [5], while a pair of meta-analysis concluded that high doses of vitamin E may increase the risk of mortality [6,7].

Obesity and being overweight are associated to insulin resistance which could appear previous to type 2 diabetes mellitus. Some years ago, it was shown that oxidative stress is increased in type 2 diabetic patients and in some studies [8], antioxidant therapy has shown beneficial effects, improving glycemic control $[9,10]$. The relation between overweight and obese subjects and 
oxidative stress has not been widely studied. Yet, it has been proven that antioxidant plasma concentrations are reduced in individuals at increased risk of diabetes [11]. Others studies have reported that Body Mass Index (BMI), correlates with systemic oxidative stress [12, 13], and that fat accumulation, closely correlates with the markers of systemic oxidative stress in non-diabetic human subjects [14]. Accordingly, antioxidant supplementation could be used as an effort to ameliorate the development of such pathology. However, there is a little documentation about the effects of AT on overweight or obese subjects [15].

Some studies have shown difficulty in getting appropriate AT plasma concentrations from foods [16]; and worse, many women do not consume vegetable oils and other vitamin E-rich food because its hypercaloric content is not attractive for modern weight control. In Mexico, the prevalence of AT deficiency among aged women was $30 \%$ according to the National Nutrition Survey in 1999, ENN, 1999 [17]. This finding suggests that understanding AT effects on middle-aged, overweight women is of capital importance.

\section{Materials and Methods}

\section{Subjects}

Ethical permission for all studies was obtained from the Hospital General de Zona No 46 of the Instituto Mexicano del Seguro Social (IMSS) Research Ethics Committee in Villahermosa, Tabasco, México. Studies were conducted according to Declaration of Helsinki principles. Subjects gave written, informed consent before participation. Sixteen healthy female subjects, between $40-60$ years old, with the characteristics shown in Table 1 were recruited from workers at the hospital. Participants were hospital employees as nurses, secretaries and medical doctors.

Table 1: Baseline characteristics of overweight healthy women $(\mathrm{n}=16)$

\begin{tabular}{lr}
\hline Characteristic & Mean \pm SD \\
\hline Age (years) & $51.8 \pm 4.47$ \\
Body weight $(\mathrm{Kg})$ & $61.59 \pm 6.77$ \\
Height $(\mathrm{m})$ & $1.53 \pm 0.04$ \\
BMI $\left(\mathrm{Kg} / \mathrm{m}^{2}\right)$ & $26.18 \pm 2.85$ \\
Systolic blood pressure* $(\mathrm{mmHg})$ & $112.5 \pm 8.56$ \\
(mmHg) & $71.13 \pm 8.56$ \\
Diastolic blood pressure* $(\mathrm{mmHg})$ & $57.90 \pm 32.65$ \\
\hline FSH (mIU/ml)
\end{tabular}

*(mmHg)

All the studied subjects were healthy as determined by a medical history questionnaire, physical examination and normal results from clinical laboratory tests. Additional criteria included menstrual period cessation or irregular menstruation, elevated follicle stimulating hormone levels ( $\geq 30 \mu \mathrm{U} / \mathrm{ml}$ ), mean body mass index over 25 but less than 30 (BMI; in $\mathrm{Kg} / \mathrm{m}^{2}$ ), hot flashes and one or both ovaries remaining. Exclusion criteria included hormonal therapy; cardiovascular, hepatic, gastrointestinal, or renal diseases; diabetes, hypertension, obesity, hyperlipidemia, supplemental vitamin use at least three months before the start of the study, along with intake of garlic or fish oil, alcoholism, smoking, or poorly accessible veins.

A dietary evaluation was conducted by a dietitian at the beginning and at the end of the study. All participants completed a 1-day food record and the dietary intake was calculated. Subjects were encouraged to maintain their diet and activities without modification throughout the study period. Participants received AT, 800 IU/day, during 12 weeks, followed by a 6-week washout period.

\section{Reagents and Blood Sample Collection}

AT was purchased from Nutricia Manufacturing, USA, in capsules containing $400 \mathrm{IU}$ of vitamin E as D- $\alpha-$ tocopherol acetate. Sulfuric and phosphotungstic acid, 2thiobarbituric acid, 1,1,2,3,-tetraethoxypropane and other chemicals were purchased from Sigma Chemical Company (St Louis, MO, USA).

Venous blood samples were obtained from participants at the beginning of the study, at 6 and 12 weeks of the AT treatment and at the end of the washout period (18 weeks). In all cases, blood samples were taken between 7:00-8:00 am after a 12 hour fasting period. Routine blood clinical determinations and erythrocyte enzyme activities were determined the same day of sample collection. Serum aliquots were preserved at $70^{\circ} \mathrm{C}$ for up 10 days for other determinations.

\section{Clinical Chemistry}

Hemoglobin concentration and blood cells count were measured using a Cell-Dyn 3700 counter from Abbott Diagnostics. Plasma triglycerides were assayed by the peroxidase-coupled method [18], total plasma cholesterol was measured by the Allain enzymatic method [19]. High density lipoproteins (HDL) cholesterol was determined after precipitation of LDL, very low-density lipoproteins and chylomicrons using $\mathrm{MgCl}_{2}$ and dextran sulphate. LDL-cholesterol concentration was calculated from the above data using the Friedewald formula [20].

Glycated hemoglobin (HbA1c) was measured by a turbidimetric immunoinhibition method. In the reaction, HbA1c antibodies were combined with hemoglobin A1c from the sample to form soluble antigen-antibody complexes. Polyhaptens from the reagent were bound with the excess of antibodies and the resulting agglutinated complex was measured turbidimetrically. Serum $\mathrm{Mg}^{2+}$ was determined by a spectrophotometric method using Magon, 1-azo-2- hydroxy-3-(2, 4dimethylcarboxanilido)naphthalene-1'-(2-hydroxybenzene). All the mentioned and other routine clinical assays were 
performed using a Synchron CX7 Clinical System, from Beckman Coulter with a daily quality control program for precision. Human follicle stimulating hormone (FSH) was measured by enzymatic immunoassay on a Abbott Axsym System (Abbott Laboratories, USA).

\section{Oxidative Stress}

The oxidative stress evaluation included the measurement of endogenous antioxidant capacity as well as biomarkers of lipid peroxidation. Total antioxidant status (TAS) in serum represents the cumulative effects of all antioxidants. It was measured by a commercial kit (Randox Lab., Grumlin, UK) based on the ability of antioxidants in the sample to inhibit the oxidation of $\operatorname{ABTS} \mathbb{R}\left(2,2^{\prime}\right.$-azino-di-[3-ethylbenzthiazoline sulphonate] to $\mathrm{ABTS} \otimes \bullet+$ by metmyoglobin. The suppression of a stable, blue green color production is proportional to the total antioxidant concentration.

Selenium dependent-glutathione peroxidase (GPx) activity in erythrocytes was measured by a commercial kit (Randox Lab), based on the method of Paglia and Valentine, using cumene hydroperoxide as substrate [21]. $\mathrm{CuZn}$-superoxide dismutase (SOD) activity from erythrocytes was measured by a commercially available kit (Randox Lab), based on the method of McCord and Fridovich [22]. AT and retinol concentrations were measured in serum by the high performance liquid chromatography (HPLC) method of Sowell et al, after a lipid extraction with a hexane-ethanol mixture [23]. Malondialdehyde (MDA) in serum was determined by its reaction with thiobarbituric acid (TBA). To prevent artificial autooxidation, butylated hydroxytoluene (BHT) in a final concentration of $15 \mu \mathrm{mol} / \mathrm{L}$ was added to the reaction mixture. To improve the extraction of the MDA-
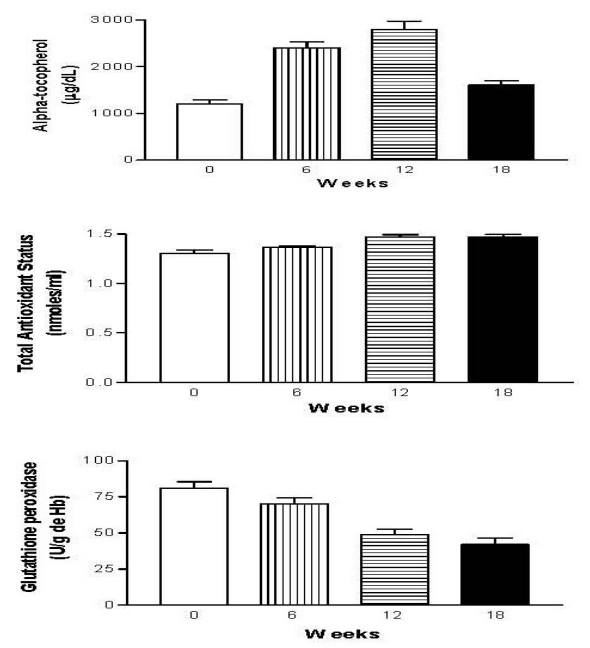

TBA adduct, $5 \mathrm{M} \mathrm{HCl}$ was used before the extraction with n-butanol according to Wasowicz et al [24]. A $1,1,3,3$ tetraethoxypropane hydrolyzed solution was used to prepare a standard curve and a microplate reader to measure the absorbance at $532 \mathrm{~nm}$.

\section{Statistical Analysis}

Statistical analysis was performed with the use of GRAPH-PAD PRISM (version 3.0; GraphPad Software, San Diego). A one way, repeated measure analysis of variance (ANOVA) for the time component of the experiment was performed. Tukey post-hoc analysis was used where appropriate to test the differences between the groups. A value of $p<0.05$ was accepted as significant.

\section{Results}

\section{Clinical Characteristics}

Table 1 shows the baseline clinical characteristics of the patients included in this study. As noted, all subjects had a sufficient ingestion of vitamins and minerals, including AT from the diet. The calculated daily energy intake was $1600 \mathrm{Kcal} / \mathrm{d}$. All the participants were overweight according to the definition of the World Health Organization. Figure 1 shows basal normal levels of AT $(1204 \pm 343.2 \mu \mathrm{g} / \mathrm{dL})$. As expected, AT concentration increased after supplementation $(p<0.001)$ which confirmed a good compliance of the participants. Table 2 shows normal baseline values of glycemic-lipidic metabolites in the subjects. According to the clinical interview, a good tolerance to AT was reported. No patients reported digestive disorders that could be attributed to this substance.
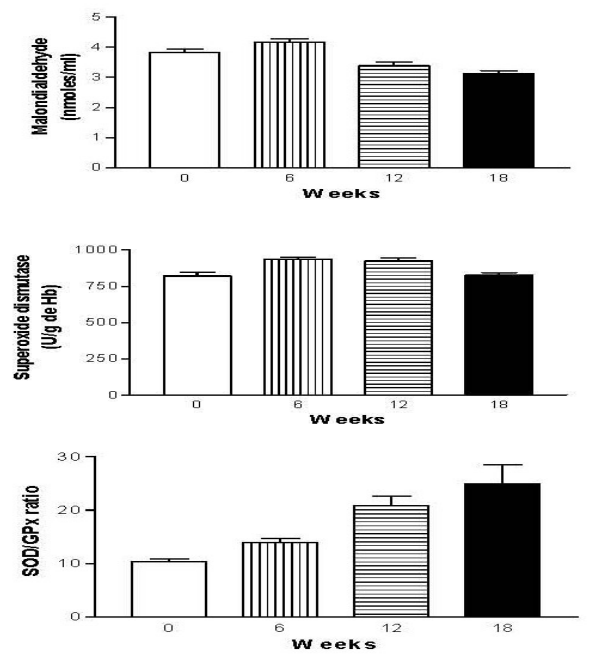

Figure 1: Effects of AT supplementation on lipid peroxidation and TAS markers. Serum MDA:Wk 0 vs wk $6, p>0.05 ; 0$ vs $12, p<0.05 ; 0$ vs $18, p<0.001$. Serum TAS: Wk 0 vs wk $12, p<0.001 ; 0$ vs $18, p<0.001 ; 6$ vs $18, p<0.05$. Erythrocyte $\mathrm{Cu} / \mathrm{Zn}$-superoxide dismutase (SOD): Wk 0 vs wk $6, \mathrm{P}<0.001 ; 0$ vs $12, p<0.001 ; 0$ vs 18, $p>0.05$. Erythrocyte Se-GPx (GPx): Wk 0 vs wk $6, p<0.01 ; 0$ vs $12, p<0.001$; 0 vs $18, p<0.001$. AT levels: Wk 0 vs wk $6, p<0.001 ; 0$ vs $12, p<0.001 ; 12$ vs $18, p<0.05$. SOD/GPx ratio: Wk 0 vs wk 12 and 0 vs $18, p$ $<0.001 ; 6$ vs $12, p<0.05 ; 6$ vs $18, p<0.001 . n=16$. 
Table 2: Modification of biochemical metabolic markers following 6 and 12 weeks of oral supplementation with $\alpha$-tocopherol 800 IU/day to overweight female subjects $(n=16)$. A washout period of 6 weeks followed the AT treatment.

\begin{tabular}{|c|c|c|c|c|c|}
\hline Parameter & Week 0 & Week 6 & Week 12 & $\begin{array}{l}\text { Week } 18 \\
\text { (Washout) }\end{array}$ & $p$ \\
\hline Glycated hemoglobin (\%) & $3.894 \pm 0.2175$ & $3.625 \pm 0.274$ & $3.131 \pm 0.2414$ & $3.244 \pm 0.1590$ & $\begin{array}{ll}0 \text { vs } 6, & \mathrm{p}<0.001 \\
0 \text { vs } 12, & \mathrm{p}<0.001 \\
0 \text { vs } 18, & \mathrm{p}<0.001 \\
6 \text { vs } 12, & \mathrm{p}<0.001 \\
6 \text { vs } 18, & \mathrm{p}<0.001 \\
12 \text { vs } 18, & \mathrm{p}>0.05\end{array}$ \\
\hline Uric Acid & $4.669 \pm 0.6416$ & $4.325 \pm 0.591$ & $4.281 \pm 0.7556$ & $4.594 \pm 0.8410$ & NS \\
\hline Cholesterol & $196.9 \pm 33.75$ & $192.2 \pm 36.60$ & $196.7 \pm 35.11$ & $194.0 \pm 42.52$ & NS \\
\hline $\begin{array}{l}\text { Cholesterol/ High density } \\
\text { lipoproteins }\end{array}$ & $3.614 \pm 0.768$ & $3.718 \pm 0.5099$ & $3.823 \pm 0.9976$ & $4.129 \pm 0.970$ & NS \\
\hline Triglycerides & $162.1 \pm 66.18$ & $159.80 \pm 72.71$ & $164.7 \pm 66.98$ & $140.2 \pm 48.73$ & NS \\
\hline Phosphates & $3.650 \pm 0.547$ & $3.494 \pm 0.763$ & $3.869 \pm 0.490$ & $3.40 \pm 0.4351$ & NS \\
\hline Magnesium & $2.089 \pm 0.2157$ & $2.104 \pm 0.1120$ & $2.305 \pm 0.1423$ & $2.024 \pm 0.2055$ & $\begin{array}{cc}0 \text { vs } 12, & \mathrm{p}<0.01 \\
6 \text { vs } 12, & \mathrm{p}<0.05 \\
12 \text { vs } 18, & \mathrm{p}<0.001\end{array}$ \\
\hline Retinol & $45.86 \pm 7.966$ & $44.60 \pm 7.682$ & $47.6 \pm 8.1$ & $43.5 \pm 6.9$ & NS \\
\hline
\end{tabular}

\section{Metabolic Profile}

No changes in glucose concentrations were observed after AT supplementation (Table 2). Nevertheless, HbA1c levels decreased time-dependently during the 12-weeks period of AT supplementation (week 0 vs 6 , and week 0 vs 12 , week 6 vs $12 ; p<0.001$ ). During the washout period AT values remained low (week 12 vs week 18; $p>0.05$; week 0 vs week 18; $p<0.001$ ) (Table 2). The lipid profile, including lipoprotein concentration, was not modified after AT treatment. Serum $\mathrm{Mg}^{2+}$ increased slightly at week 6 but was significantly different at week 12 of AT treatment (week 0 vs $6 ; p>0.05$; week 0 vs $12 ; p<0.01$ ). During the washout period, values returned close to baseline concentrations (week 0 vs $18, p>0.05$; week 12 vs $18 ; p<0.001)$.

\section{Oxidative Stress Markers}

Figure 1 shows the effects of AT on oxidative stress biomarkers. Serum concentration of MDA was not different from baseline level at week 6 but was significantly lower at week 12 after AT treatment (week 0 vs week $6, p>0.05$; week 0 vs week $12 ; p<0.05)$. After the washout period it remained low with respect to baseline value (week 0 vs week $18 ; p<0.001$ ).
AT serum concentrations were duplicated after 6 weeks of supplementation but were only $30 \%$ higher at week 12 (week 0 vs week $6 ; p<0.001$, week 6 vs week 12 ; $p<0.01)$. As expected, a reduction occurred at the end of the washout period (week 12 vs week $18 ; p<0.05$ ). Serum retinol concentrations were not modified during the experimental period (data not shown). The TAS serum concentration showed a tendency to increase after AT treatment (Figure 1).

This increase was only significant at week 12 (week 0 vs week $12 ; p<0.001)$. The increased levels remained high after the washout period (week 0 vs week 18; $p<0.001)$. Erythrocyte SOD activity increased after the AT treatment at week 6 and stayed at this level until week 12 (week 0 vs week $6 ; p<0.001$, week 0 vs week 12 ; $p<0.001)$. After the washout period these levels diminished to baseline values (week 0 vs week 18; $p>0.05$ ) (Figure 1). A continuous reduction in erythrocyte GPx activity was observed throughout the AT treatment (week 0 vs week $6 ; p<0.01$, week 0 vs week $12 ; p<0.001$ ). These diminished values remained the same after the washout period. As a result of the SOD increase and GPx reduction the ratio of $\mathrm{SOD} / \mathrm{GPx}$ in erythrocytes progressively augmented under AT treatment (weeks: 0 vs 12 and 0 vs $18 ; p<0.001$; weeks: 6 vs $12, p<0.05$; weeks: 6 vs 18, $p<0.001$ ) (Figure 1). 


\section{Discussion}

Several reports have concluded that the best effect of AT supplementation could result from its intake before the onset of chronic diseases. Under these conditions, AT more efficiently reduces the initial oxidation caused by reactive oxygen species [25]. In the present study, AT effects on mildly overweight women was explored. The importance of studying subjects in the slightly overweight BMI range has been expressed in some studies, where a high prevalence of metabolic syndrome is observed [26]. Metabolic syndrome is a multifactorial condition associated with high mortality rate and major cardiovascular events [27]. The key pathogenic mechanism of this syndrome is attributed to insulin resistance which is related to being overweight in most cases. A close link among the metabolic syndrome, a state of chronic low-level inflammation and oxidative stress has been established [28]. In general, pro-oxidative conditions in the cell lead to production of reactive aldehydes such as malondialdehyde (MDA).

The serum-MDA concentrations found in this study were not unlike from those in a group of healthy women with normal weight $(\mathrm{BMI}=24.5, \mathrm{n}=30, \mathrm{MDA}=3.26 \pm 0.6$ $\mathrm{nmol} / \mathrm{ml}$ ). Yet, other studies have found a linear relation between fat accumulation and oxidative stress. In a group of obese subjects, a strong association between increased abdominal fat storage and MDA serum concentrations was observed. In that particular report, patients with obesity $(\mathrm{BMI}=33 \pm 6)$ and metabolic syndrome were included [29]. In this study, serum MDA reduction was observed on week 12 of AT treatment and this decreasing tendency was maintained after the washout period. This finding is consistent with Upritchard, who reported lipoperoxidation reduction in healthy subjects after $111 \mathrm{mg} / \mathrm{d}$ AT during 11 weeks [30]. Furthermore, Sutherland reported 11\% reduction on plasma 8 -isoprostane concentration after vitamin E $800 \mathrm{IU} / \mathrm{d}$ by three months and 1,200 IU/d for an additional three months in overweight subjects [31]. Yet, some authors have not found such a reduction on healthy subjects [32]. Moreover, a pro-oxidant effect of AT (1,200 IU/d for $4 \mathrm{wk}$ ) associated with increased DNA damage has been observed in patients with type 2 diabetes [4]. Therefore, further studies are still needed to clarify the effects of high doses of vitamin E.

Although not as specific as 8-isoprostane determination to evaluate lipoperoxidation, MDA determination by the TBA reaction is the most extensive method reported in the literature. In applying this method, BHT was used as an antioxidant to inhibit the artifact formation of lipid peroxides. During the assay an acidification was used before the extraction of the MDATBA adduct to improve recuperation [24].

In this trial, we did not discover modification on serum fasting glucose levels; nevertheless, we did observe a $\mathrm{HbAlc}$ percentage diminished in a time-dependent fashion along the AT treatment and it remained low at the end of the washout period. In another study of uncontrolled female type 2 diabetics, we did not observe changes on glycemic control markers after six weeks of $800 \mathrm{UI} / \mathrm{d}$ AT supplementation [33]. The effect of AT on glycemic control is unclear, while some studies have reported a HbA1c reduction after AT treatment [9, 34], others do not support this result [35].

An increment of serum $\mathrm{Mg}^{2+}$ levels after 12 weeks of AT supplementation was observed. At the end of the washout period, these values decreased to baseline levels. The relevance of this finding is derived from the knowledge that $\mathrm{Mg}^{2+}$ and $\mathrm{Ca}^{2+}$ are cations that participate in regulating cellular glucose homeostasis and insulin sensitivity [36]. The $\mathrm{Mg}^{2+}$ supplementation has shown a beneficial effect in type 2 diabetes mellitus and chronic fatigue syndrome [36, 37]. In patients with chronic fatigue syndrome, $\mathrm{Mg}^{2+}$ supplementation produced an increment in serum vitamin E [38]. Also, vitamin E treatment increased intracellular $\mathrm{Mg}^{2+}$ concentration in type 2 diabetic patients [39]. The hypothesis is that the effect of AT on intracellular magnesium content leads to a reduction in intracellular calcium content, resulting in an improved smooth vascular cell relaxation.

The participants in this study exhibited AT normal plasma levels at the baseline. During AT supplementation, these levels increased depending on time (Figure 1), confirming the compliance. The observed increment in serum TAS levels after AT could be attributed to the increased AT concentration.

An increase in erythrocyte SOD and a reduction in GPx activities were observed after AT supplementation in this study. Consequently, an increase in the SOD/GPx ratio was also estimated. It is understood that SOD catalyzes the dismutation of superoxide anion to hydrogen peroxide and GPx, the conversion of $\mathrm{H}_{2} \mathrm{O}_{2}$ to $\mathrm{H}_{2} \mathrm{O}$. Any increase in SOD catalytic activity produces an excess of $\mathrm{H}_{2} \mathrm{O}_{2}$ that must be efficiently neutralized by Gpx. The accumulation of $\mathrm{H}_{2} \mathrm{O}_{2}$ when it is not efficiently converted to $\mathrm{H}_{2} \mathrm{O}$ may be detrimental to cells. For this reason, disequilibrium between SOD and GPx activity ratio has been proposed as a marker of oxidative stress [40, 41]. During our study, we expected that increased plasma AT concentrations would preserve the consumption of GSH and GPx enzyme activities in erythrocytes, which result in a conservation or increase of this marker. We do not have an explanation for the reduced GPx activity observed. Reports about enzyme activity changes are controversial. Vitamin E supplementation $(280 \mathrm{mg} / \mathrm{d})$ for 10 weeks increased GPx and glutathione reductase activities but decreased SOD activity and GSH content in erythrocytes from nonsmoking men [42]. Other studies have shown no effect of vitamin E, in adolescents with type 1 diabetes. Vitamin E supplementation $(1,200 \mathrm{mg} / \mathrm{d}$ for three months) did not modify the defective intracellular antioxidant enzymes production in skin fibroblasts [43]. In addition, in rats fed salmon oil, high doses of vitamin $\mathrm{E}$ diminished the activities of erythrocyte GPx and catalase [44].

This study has some limitations that should be knowledge. As the study was done only on women, we 
cannot be certain that similar effects could be achieved in men. The age ranges of the participants are included among the period with the higher overweight incidence in our country [45]. Our study was conducted without a strict dietary control. This condition should be included in future research in order to understand the complicated interactions among AT supplementation and the activities of antioxidant enzymes. Moreover, a group of control group with placebo would have been desirable.

\section{Conclusions}

In conclusion, the AT at doses used here, was well tolerated and showed potential clinical benefits from the reduction on serum lipid peroxidation, the increase in serum TAS, SOD activity and serum $\mathrm{Mg}^{2+}$. But the implication of the imbalance between erythrocyte-SOD and -GPx activities is not clear and requires further research because it could eventually affect the normal response of healthy people to oxidative stress.

Author's contributions: JDM, JCDZ, GCV and RMS participated in the study design. JLBC coordinated the trial, performed the analytic assays and wrote the initial draft of the manuscript. GCV, JDM, HRA and JCDZ assisted in the interpretation of the results and contributed to the editing and review of the manuscript.

Acknowledgments: We thank all the volunteers who participated in this study. We express our appreciation to chemists Irene Montalvo Velarde and Ruben Cordova Uscanga, and biologist Elizabeth Carmona Díaz for their support and assistance. This study was supported by a grant to JLBC from the Fondo de Fomento a la Investigación of the Instituto Mexicano del Seguro Social (IMSS, FP 2003/052). Dr. Hector Rubio Helped in the statistical analysis and proper edition of this paper, therefore, he was invited to be co-author of this manuscript. Jorge Ble-Castillo is a member of the Programa para el Mejoramiento del Profesorado de Educación Superior (PROMEP-103.5/03/2178-UJATAB148) and a fellow Doctor at the Escuela Superior de Medicina del IPN, México, D.F.

\section{References}

1. González-Correa, J. A.; Arrebola, M. M.; Guerrero, A.; Cañada, M. J.; Muñoz-Marín, J.; Sánchez de la Cuesta, F.; De la Cruz, J. P.: Antioxidant and antiplatelet effects of the alpha-tocopherol-aspirin combination in type 1-like diabetic rats. Life Sciences, 2006, 79, 1405-1412.

2. Mustacich, D. J.; Leonard, S. W.; Devereaux, M. W.; Sokol, R. J.; Traber, M. G.: $\alpha$-tocopherol regulation oh hepatic cytochrome P450s and ABC transporters in rats. Free Rad Biol Med, 2006, 41, 1069-1078.

3. Brown, K. M.; Morrice, P. C.; Duthie, G. G.: Erythrocyte vitamin $\mathrm{E}$ and plasma ascorbate concentrations in relation to erythrocyte peroxidation in smokers and nonsmokers. Dose response to vitamin E supplementation. Am J Clin Nutr, 1997, 65, 496-502.

4. Winterbone, M. S.; Sampson, M. J.; Saha, S.; Hughes, J. C.; Hughes, D. A.: Pro-oxidant effect of $\alpha$ tocopherol in patients with Type 2 Diabetes after an oral glucose tolerance test-a randomized controlled trial. Cardiovasc Diabetol, 2007, 6:8.

5. Hatchcock, J. N.; Azzi, A.; Blumberg, J.; Bray, T.; Dickinson, A.; Frei, B.; Jialal, I.; Johnston, C. S.; Kelly, F. J.; Kraemer, K.; Packer, L.: Vitamin E and $\mathrm{C}$ are safe across a broad range of intakes. Am J Clin Nutr. 2005, 81, 736-45.

6. Bjelakovic, G.; Nikolova, D.; Simonetti, R. G.; Gluud, C.: Antioxidant supplements for prevention of gastrointestinal cancers: a systematic review and meta-analysis. Lancet, 2004, 364, 1219-1228.

7. Miller, E. R.; Pastor-Barriuso, R.; Dalal, D.; Riemersma, R. A.; Appel, L. J.; Guallar, E.: Metaanalysis: high-dosage vitamin E supplementation may increase all-cause mortality. Ann Intern Med, 2005, 142, 37-46.

8. Skrha, J.; Sindelka, G.; Kvasnicka, J.; Hilgertova, J.: Insulin action and fibrinolysis influenced by vitamin E in obese type 2 diabetes mellitus. Diabetes Res Clin Pract, 1999, 44, 27-33.

9. Paolisso, G.; D’Amore, A.; Galzerano, D.; Balbi, V.; Giugliano, D.; Varricchio, M.; D'Onofrio, F.: Daily vitamin E supplements improve metabolic control but not insulin secretion in elderly type II diabetic patients. Diabetes Care, 1993, 16, 1433-1437.

10. Jacob, S.; Ruus, P.; Hermann, R.; Tritschler, H. J.; Maerker, E.; Renn, W.; Augustin, H. J.; Dietze, G. J.; Rett, K.: Oral administration of RAC- $\alpha$-lipoic acid modulates insulin sensitivity in patients with type 2 diabetes mellitus: a placebo-controlled pilot trial. Free Rad Biol Med, 1999, 27, 309-314.

11. Ford, E. S.; Mokdad, A. H.; Giles, W. H.; Brown, D. W.: The metabolic syndrome and antioxidant concentrations: findings from the Third National Health and Nutrition Examination Survey. Diabetes. 2003, 52, 2346-2352.

12. Keaney, J. F. Jr, ; Larson, M. G.; Vasan, R. S.; Wilson, P. W.; Lipinska, I.; Corey, D.; Massaro, J. M.; Sutherland, P.; Vita, J. A.; Benjamin, E. J.: Obesity and systemic oxidative stress: clinical correlates of oxidative stress in the Framingham Study. Arterioscler Thromb Vasc Biol, 2003, 23, 434-439.

13. Olusi, S. O.: Obesity is an independent risk factor for plasma lipid peroxidation and depletion of erythrocyte cytoprotectic enzymes in humans. Int $J$ Obes Relat Metab Disord, 2002, 26, 1159-1164.

14. Furukawa, S.; Fujita, T.; Shimabukuro, M.; Iwaki, M.; Yamada, Y.; Nakajima, Y.; Nakayama, O.; Makishima, M.; Matsuda, M.; Shimomura, I.: Increased oxidative stress in obesity and its impact on metabolic syndrome. J Clin Invest, 2004, 114, 1752-1761. 
15. Manning, P. J.; Sutherland, W. H. F.; Walker, R. J.; Williams, S. M.; de Jong, S. A.; Ryalls, A. R.: Effect of high-dose vitamin $\mathrm{E}$ on insulin resistance and associated parameters in overweight subjects. Diabetes Care, 2004, 27, 2166-2171.

16. McGavin, J. K.; Mann, J. I.; Skeaff, C. M.; Chisholm, A.: Comparison of a vitamin E-rich diet and supplemental vitamin $\mathrm{E}$ on measures of vitamin $\mathrm{E}$ status and lipoprotein profile. Eur J Clin Nutr, 2001, 55, 555-561.

17. National Nutrition Survey. Nutritional status of children and women in Mexico. Mexico Department of Health. Nutrition. (ENN-99). 1999. Internet: http://www.salud.gob.mx/unidades/cdi/documentos/n utrición.pdf (accessed March 10, 2006).

18. Bucolo, G.; David, H.: Quantitative determination of serum triglycerides by the use of enzymes. Clin Chem 1973, 19, 476-482.

19. Allain, C. C.; Poon, L. S.; Chanm, C. S.; Richmond W.; Fu, P. C.: Enzymatic determination of total serum cholesterol. Clin Chem, 1974, 20, 470-475.

20. Friedewald, W. T.; Levy, R. I. Fredrickson, D. S.: Estimation of the concentration of low-density lipoprotein cholesterol in plasma, without use of the preparative ultracentrifuge. Clin Chem, 1972, 18, 499-502.

21. Paglia, D. E.; Valentine, W. N.: Studies on the quantitative and qualitative characterization of erythrocyte glutathione peroxidase. J Lab Clin Med, 1967, 70, 158-169.

22. McCord, J. M.; Fridovich, I.: Superoxide dismutase. An enzymatic function for erythrocuprein (hemocuprein). J Biol Chem, 1969, 244, 6049-6055.

23. Sowell, A. L.; Huff, D. L.; Yeager, P. R.; Caudill, S. P.; Gunter, E. W.: Retinol, alpha-tocopherol, lutein/zeaxanthin, beta-cryptoxanthin, lycopene, alpha-carotene, trans-beta-carotene and four retinyl esters in serum, determined simultaneously by reversed-phase HPLC with multiwavelength detection. Clin Chem. 1994, 40, 411-416.

24. Wasowicz, W.; Neve, J.; Peretz, A.: Optimized steps in fluorometric determination of thiobarbituric acidreactive substances in serum: importance of extraction $\mathrm{pH}$ and influence of sample preservation and storage. Clin Chem, 1993, 39, 2522-2526.

25. Brigelius-Flohé, R.; Kelly, F. J.; Salonen, J. T.; Neuzil, J.; Sing, J. M.; Azzi, A.: The European perspective on vitamin E: current knowledge and future research. Am J Clin Nutr, 2002, 76, 703-716.

26. St-Onge, M. P.; Janssen, I.; Heymsfield, S. B.: Metabolic syndrome in normal-weight Americans. New definition of the metabolically obese, normal-weight individual. Diabetes Care, 2004, 27, 2222-2228.

27. McNeill, A. M.; Rosamond, W. D.; Girman, C. J.; Golden, S. H.; Schmidt, M. I.; East, H. E.; Ballantyne, C. M.; Heiss, G.: The metabolic syndrome and 11year risk of incident cardiovascular disease in the atherosclerosis risk in communities study. Diabetes Care, 2005, 28, 385-390.
28. Wellen, K. E.; Hotamisligil, G. S.: Inflammation, stress, and diabetes. J Clin Invest, 2005, 115, 11111119.

29. Palmieri, V. O.; Grattagliano, I.; Portincasa, P.; Palasciano, G.: Systemic oxidative alterations are associated with visceral adiposity and liver steatosis in patients with metabolic syndrome. J Nutr, 2006, 136, 3022-3026.

30. Upritchard, J. E.; Schuurman, C. R.; Wiersma, A.; Tijburg, L. B.; Coolen, S. A.; Rijken, P. J.; Wiseman, S. A.; Spread supplemented with moderate doses of vitamin $\mathrm{E}$ and carotenoids reduces lipid peroxidation in healthy, nonsmoking adults. Am J Clin Nutr. 2003, 78, 985-992.

31. Sutherland, W. H. F.; Manning, P. J.; Walker, R. J.; de Jong, S. A.; Ryalls, A. R.; Bery, E. A.: Vitamin E supplementation and plasma 8-isoprostane and adiponectin in overweight subjects. Obesity, 2007, 15, 386-391.

32. Meagher, E. A.; Barry, O. P.; Lawson, J. A.; Rokach, J. R.; FitzGerald, G. A.: Effects of vitamin E on lipid peroxidation in healthy persons. JAMA, 2001, 285, 1178-1182.

33. Ble-Castillo, J. L.; Carmona-Díaz, E.; Mendez, J. D.; Larios-Medina, F. J.; Medina-Santillán, R.; ClevaVillanueva, G. G.; Diaz-Zagoya, J. C.: Effect of alpha-tocopherol on the metabolic control and oxidative stress in female type 2 diabetics. Biomed Pharmacother, 2005, 59, 290-295.

34. Ceriello, A.; Giugliano, D.; Quatraro, A.; Donzella, C.; Dipalo, G.; Lefebvre, P. J.: Vitamin E reduction of protein glycosylation in diabetes. New prospect for prevention of diabetes complications? Diabetes Care 1991, 14, 68-72.

35. Lonn, E.; Yusuf, S.; Hoogwerf, B.; Pogue, J.; Yi, Q.; Zinman, B., Bosch, J.; Dagenais, G.; Mann, J. F.; Gerstein, H. C.: Effects of vitamin $\mathrm{E}$ on cardiovascular and microvascular outcomes in highrisk patients with diabetes: results of the HOPE study and MICRO-HOPE substudy. Diabetes Care, 2002, 25, 1919-1927.

36. Rodríguez-Morán, M.; Guerrero-Romero, F.: Oral magnesium supplementation improves insulin sensitivity and metabolic control in type 2 diabetic subjects. A randomized double-blind controlled trial. Diabetes Care, 2003, 26, 1147-1152.

37. McLean, R. M.: Magnesium and its therapeutic uses. Am J Med, 1994, 96, 63-76.

38. Manuel y Keenoy, B.; Moorkens, G.; Vertommen, J.; Noe, M., Nève, J.; De Leeuw, I.: Magnesium status and parameters of the oxidant-antioxidant balance in patients with chronic fatigue: Effects of supplementation with magnesium. J Am Coll Nutr, 2000, 19, 374-382.

39. Paolisso, G.; Tagliamonte, M. R.; Barbieri, M.; Zito, G. A.; Gambardella, A.; Varricchio, G.; Ragno, E.; Varricchio, M.: Chronic vitamin E administration improves brachial reactivity and increases intracellular 
magnesium concentration in Type II diabetic patients. $J$ Clin Endocrinol Metab, 2000, 85, 109-115.

40. Michiels, C.; Raes, M.; Toussaint, O.; Remacle, J.: Importance of Se-glutathione peroxidase, catalase, and $\mathrm{Cu} / \mathrm{Zn}-\mathrm{SOD}$ for cell survival against oxidative stress. Free Radic Biol Med, 1994, 17, 235-248.

41. de Haan, J. B.; Cristiano, F.; Iannello, R.; Bladier, C.; Kelner, M. J.; Kola, I.: Elevation in the ratio of $\mathrm{Cu} / \mathrm{Zn}$-superoxide dismutase to glutathione peroxidase activity induces features of cellular senescence and this effect is mediated by hydrogen peroxide. Hum Mol Genet, 1996, 5, 283-292.

42. Brown, K. M.; Morrice, P. C.; Arthur, J. R.; Duthie, G. G.: Effects of vitamin E supplementation on erythrocyte antioxidant defense mechanisms of smoking and non-smoking men. Clin Sci, 1996, 91,
107-111.

43. Chiarelli, F.; Santilli, F.; Sabatino, G.; Blasetti, A.; Tumini, S.; Cipollone, F., Mezzetti, A.; Verrotti, A.: Effects of vitamin E supplementation on intracellular antioxidant enzyme production in adolescents with type 1 diabetes and early microangiopathy. Ped Res, 2004, 56, 720-725.

44. Eder, K.; Flader, D.; Hirche, F.; Brandsch, C.: Excess dietary vitamin $\mathrm{E}$ lowers the activities of antioxidative enzymes in erythrocytes of rats fed salmon oil. $J$ Nutr, 2002, 132, 3400-3404.

45. Olaiz-Fernández, G.; Rivera-Dommasco, J.; ShamahLevy, T.; Rojas, R.; Villalpando-Hernández, S.; Hernández-Avila, M.: Encuesta Nacional de Salud y Nutrición. Cuernavaca, México: Instituto Nacional de Salud Pública, 2006. 